\title{
Novel Separation Technique of Particle Reinforced Metal Matrix Composites by Fused Deposition Method
}

\author{
Masayuki Mizumoto ${ }^{1, a}$, Takeshi Ohgai ${ }^{1, b}$ and Akio Kagawa ${ }^{1, c}$ \\ ${ }^{1}$ Department of Materials Science and Engineering, Nagasaki University, 1-14 Bunkyo-machi, \\ Nagasaki 852-8521, JAPAN \\ amizumoto@net.nagasaki-u.ac.jp, ohgai@net.nagasaki-u.ac.jp, ${ }^{\mathrm{C}}$ akagawa@net.nagasaki-u.ac.jp
}

Keywords: Recycle, Particle reinforced metal matrix composite, Separation, Fused deposition method

\begin{abstract}
To develop a novel separation technique of matrix alloys from metal matrix composite, separation experiments for various kinds of particle reinforced metal matrix composites (PRMMCs) were carried out. The Al-4mass\%Cu alloy, Al-7mass\%Si alloy and cast iron were used as matrix. The SiC particles (particle size: $75 \mu \mathrm{m}$ ) and $\mathrm{Al}_{2} \mathrm{O}_{3}$ particles (particle size: $120 \mu \mathrm{m}$ ) were used as reinforcement. The PRMMC specimen was placed in a silica tube container with a small nozzle (nozzle size: $0.75 \mathrm{~mm}$ ) at the bottom and was melted by H.F. induction heating. Then the molten PRMMC specimen was forced to flow out through the nozzle by applying a certain pressure of Ar gas. Most of the molten matrix alloy flowed out through the nozzle and the remainder in the container consisted of the reinforcements and a part of the matrix alloy. The amount of separated matrix alloy increased with decreasing the volume fraction of reinforcement particles in PRMMC specimens. With decreasing the fabrication temperature from $1273 \mathrm{~K}$ to $1073 \mathrm{~K}$, the amount of matrix alloy separated from $\mathrm{SiC}_{\mathrm{P}} / \mathrm{Al}-7$ mass\%Si alloy composites increased. It is considered that a reaction layer formed on the surface of $\mathrm{SiC}$ particles at $1273 \mathrm{~K}$ improves the wettability between the molten matrix alloy and $\mathrm{SiC}$ particle, which prevents the separation of molten matrix alloy from reinforcements. On the other hand, the amount of separated matrix alloy from 20vol\% $\mathrm{Al}_{2} \mathrm{O}_{3 \mathrm{P}} /$ cast iron composites was very high due to no reaction layer formed at interface between $\mathrm{Al}_{2} \mathrm{O}_{3}$ particle and cast iron.
\end{abstract}

\section{Introduction}

Nowadays, the application of MMCs has been extended to various industrial fields, especially, to aerospace and automotive parts due to their light weight as well as outstanding mechanical and physical properties [1, 2]. The amount of waste MMCs will increase with extension of the application of MMCs. From viewpoint of saving resources and protection of environment, recycle of waste MMCs will be a major problem in near future. For recycle of waste MMCs, it is necessary to separate MMCs into reinforcements and matrix alloy. Some physical and mechanical processes have been proposed [3, 4]. However, the efficiency of these separation techniques is not satisfactory. In our earlier works, the authors have found that most of matrix alloy was separated from PRMMCs in the experiments of fused spinning deposition method (FSD method) [5, 6]. This phenomenon is expected to apply as a novel separation technique for MMCs. In this study, separation experiments for various kinds of PRMMCs were carried out and the effect of various experimental parameters on the separation process was investigated.

\section{Experimental Procedure}

In the present work, PRMMC specimens for separation experiments were fabricated by a low pressure infiltration process (LPI process) [7-11]. The Al-4mass\% Cu alloy, Al-7mass\% Si alloy and cast iron (FC200) were used as matrix. The SiC particles (particle size: $75 \mu \mathrm{m}$ ) and $\mathrm{Al}_{2} \mathrm{O}_{3}$ particles (particle size: $120 \mu \mathrm{m}$ ) were used as reinforcement. The volume fraction of reinforcement particles in PRMMC specimens was varied from 10 to 30vol\%. The microstructure of PRMMC specimens was examined 
using optical microscope, EDX-SEM and TEM. In the case of SiC particle reinforced Al-Si alloy composite, it has been reported that a reaction between molten matrix alloy and SiC particles was suppressed at temperatures lower than 1073K [12]. To investigate the effect of reaction layer on the separation efficiency, the SiC particle/Al-7mass\%Si composites were fabricated at $1073 \mathrm{~K}$ and $1273 \mathrm{~K}$. Schematic drawing of the experimental setup for the separation experiment is shown in Fig. 1. In the separation experiment, PRMMC specimen was placed in a silica tube container with a nozzle at the bottom and was melted by H.F. induction heating. The molten PRMMC specimen was forced to flow out through the nozzle by applying a certain pressure of Ar gas on the melt surface as soon as the melt temperature reached a predetermined temperature. The separated matrix alloy was stored in the graphite crucible. After separation experiment, the microstructures of the remainder in the container and the separated matrix alloy were observed with optical microscope. The recovery of the matrix alloy was defined by the ratio of the weight of separated matrix alloy to the weight of matrix in PRMMC before separation.

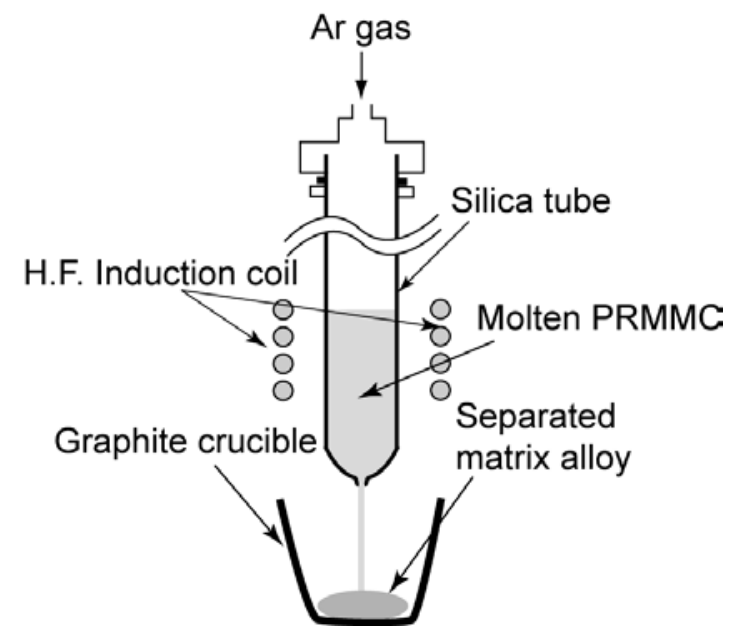

Fig. 1 Schematic drawing of the apparatus for separation experiment.

\section{Results and Discussion}

Separation process by fused deposition method. Figure 2(a) shows the microstructure of 20 vol\% $\mathrm{SiC}_{\mathrm{P}} / \mathrm{Al}-\mathrm{Cu}$ alloy composite before separation experiment. The particle distribution in the specimen seems to be homogeneous. After remelting at $1273 \mathrm{~K}$, the molten specimen was flowed out through the nozzle by applying a pressure of 0.25 MPa. Figure 2(b) and (c) show the microstructures of the remainder in the container and the separated matrix alloy, respectively. No reinforcement particle was observed in the separated matrix alloy as shown in Fig. 2(c). The volume fraction of SiC particles in the remainder seems to become higher than that in the PRMMC specimen before separation experiment. The volume fraction of $\mathrm{SiC}$ particles on different locations in the remainder was measured by image analysis. Figure 3 shows the macrostructure of the remainder in the container. White lines in the figure indicate the outline of the silica tube container near the nozzle part. The particle volume fraction in the remainder was increased towards the bottom of the container, that is, the nozzle part.It is considered that $\mathrm{SiC}$ particles move downwards with a flow of the molten matrix alloy and contact with each other, resulting in the formation of a loose skeleton structure near the nozzle part. This skeleton structure would work as a filter to separate SiC particles from the matrix alloy melt.
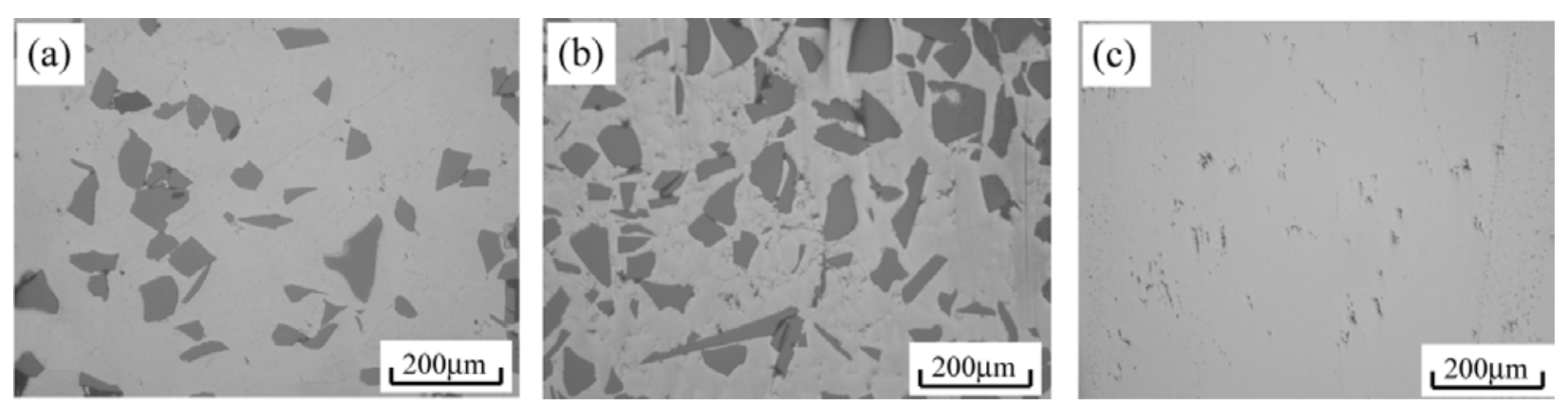

Fig. 2 Microstructure of (a) 20vol\% $\mathrm{SiC}_{\mathrm{P}} / \mathrm{Al}-\mathrm{Cu}$ alloy composites before separation experiment,

(b) remainder in the container and (c) matrix alloy flowed out through the nozzle. 


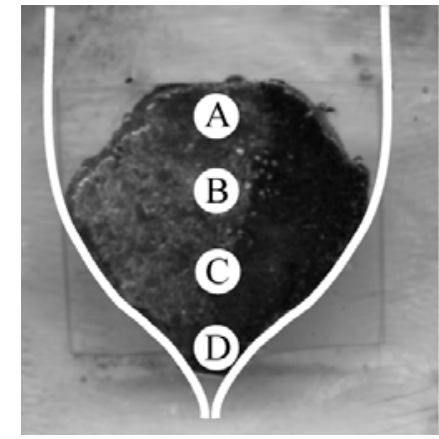

\begin{tabular}{|c|c}
\hline & $\begin{array}{l}\text { Particle volume } \\
\text { fraction (\%) }\end{array}$ \\
\hline \hline A & 28 \\
\hline B & 30 \\
\hline C & 32 \\
\hline D & 35 \\
\hline
\end{tabular}

Fig. 3 Macrostructure and particle volume fraction in the remainder for $20 \mathrm{vol} \% \mathrm{SiC} / \mathrm{Al}-\mathrm{Cu}$ alloy composites.

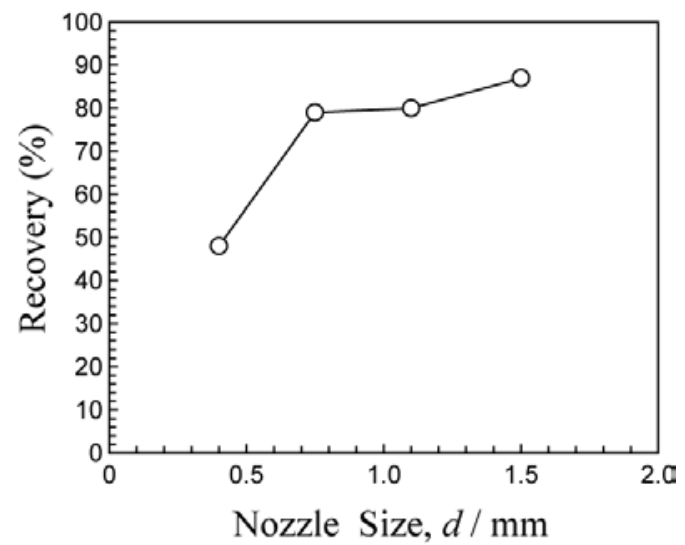

Fig. 4 The relationship between recovery and the nozzle size in $20 \mathrm{vol} \% \mathrm{SiC} / \mathrm{Al}-\mathrm{Cu}$ alloy composites.

Effect of nozzle size on separation process. In the separation technique of PRMMCs developed in this study, the reinforcement particle can be separated from the matrix alloy melt despite that particles size $(75 \sim 120 \mu \mathrm{m})$ of the reinforcements is much smaller than the nozzle size. It is expected that the nozzle size will influence the separation process significantly. To investigate the effect of nozzle size on the separation efficiency, that is, recovery, separation experiments were carried out for 20 vol\% $\mathrm{SiC}_{\mathrm{P}} / \mathrm{Al}-\mathrm{Cu}$ alloy composites (remelting temperature: $1273 \mathrm{~K}$ ) by using the containers with various nozzle size. The nozzle size was varied from 0.4 to $1.5 \mathrm{~mm}$ in diameter. Figure 4 shows the relationship between the recovery and the nozzle size. The recovery increases gradually with increasing the nozzle size. However, when the nozzle size was greater then $1.1 \mathrm{~mm}$ in diameter, SiC particles were observed in the separated matrix alloy. Thus it is suggested that the optimum nozzle size for the separation of PRMMCs is around $0.75 \mathrm{~mm}$ in this study.

Effect of applied pressure and particle volume fraction on separation process. Figure 5 shows the relationship between the recovery and applied pressure for $\mathrm{SiC}_{\mathrm{P}} / \mathrm{Al}-\mathrm{Cu}$ alloy composites with various particle volume fractions (remelting temperature: $1273 \mathrm{~K}$ ). In the case of that the particle volume fraction of the PRMMC specimen is lower than $20 \mathrm{vol} \%$, the recovery tends to decrease gradually when the applied pressure was over $0.25 \mathrm{MPa}$. When the applied pressure is $0.3 \mathrm{MPa}$, the recovery is almost half of that for the applied pressure of $0.25 \mathrm{MPa}$. The schematic illustration of the behavior of reinforcement particles during separation process is shown in Fig. 6. When the applied pressure is low, the reinforcement particles move slowly with a downward flow of molten matrix alloy and form a skeleton structure near the nozzle as shown in Fig. 6(a). On the other hand, when the applied pressure is high, a preferential flow path is formed in PRMMC specimen at an early stage of the separation process shown in Fig. 6(b) and the applied pressure escapes through the preferential flow path, leading to no further separation. Therefore it is suggested that an optimum applied pressure is around $0.25 \mathrm{MPa}$.

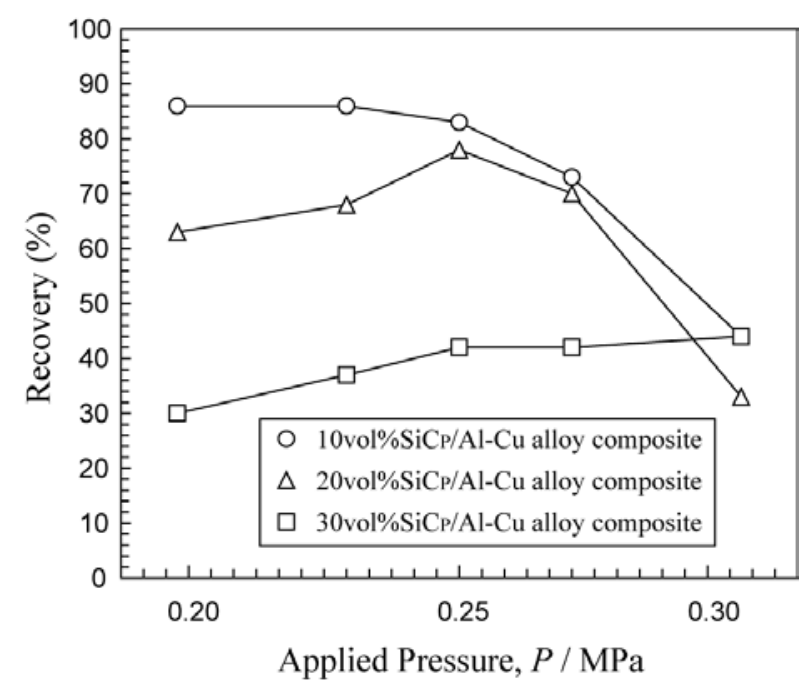

Fig. 5 The relationship between recovery and applied pressure in $\mathrm{SiC}_{\mathrm{p}} / \mathrm{Al}-\mathrm{Cu}$ alloy composites with various particle volume fractions. 
In Fig. 5, the recovery decreases with increasing the volume fraction of reinforcement particles and the recovery of $30 \mathrm{vol} \% \mathrm{SiC}_{\mathrm{P}} / \mathrm{Al}-\mathrm{Cu}$ alloy composite is hardly changed, independent of applied pressure, and much lower than that of other specimens when the applied pressure was lower than $0.27 \mathrm{MPa}$. This large decrease in the recovery of 30 vol\% $\mathrm{SiC}_{\mathrm{P}} / \mathrm{Al}-\mathrm{Cu}$ alloy composite is considered to result from the particle volume fraction in the specimen, which is close to the particle volume fraction where a skeleton structure is formed near the nozzle as mentioned before. The result indicates that the separation technique developed in this study is effective for PRMMC specimens with particle volume fraction lower than $30 \mathrm{vol} \%$.

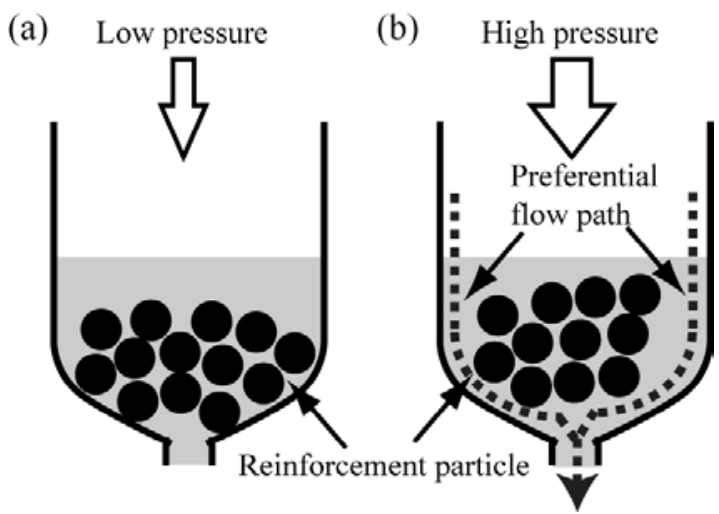

Fig. 6 Schematic illustration of the behavior of reinforcement particles during separation process at (a) low pressure and (b) high pressure.

Effect of wettability between reinforcement particles and molten matrix alloy on the recovery. It has been reported that the wettability between ceramics reinforcement and molten metal would be improved by the formation of a reaction product [13]. An appropriate reaction product will improve the bonding strength between reinforcement and matrix alloy [9]. However, it is expected that the improvement of wettability between reinforcement and matrix will prevent the separation process. To investigate the effect of interface reaction on the recovery, separation experiments were carried out for $\mathrm{SiC}_{\mathrm{P}} / \mathrm{Al}-\mathrm{Si}$ alloy composite and $\mathrm{Al}_{2} \mathrm{O}_{3 \mathrm{P}}$ /cast iron (FC200) composite. As mentioned before, the reaction between $\mathrm{SiC}$ particles and $\mathrm{Al}-7 \mathrm{mass} \% \mathrm{Si}$ alloy melt is suppressed when the temperature of alloy melt is lower than $1073 \mathrm{~K}$ [12]. Thus $20 \mathrm{vol} \% \mathrm{SiC}_{\mathrm{P}} / \mathrm{Al}-\mathrm{Si}$ alloy composites fabricated at $1073 \mathrm{~K}$ and $1273 \mathrm{~K}$ were prepared. The result of separation experiments were summarized in Table 1 . The recovery for the $\mathrm{SiC}_{\mathrm{P}} / \mathrm{Al}-\mathrm{Si}$ alloy composite fabricated at $1073 \mathrm{~K}$ is higher than that for the composite fabricated at $1273 \mathrm{~K}$. In the case of $\mathrm{Al}_{2} \mathrm{O}_{3 \mathrm{P}}$ /cast iron (FC200) composite, the recovery is very high (94\%), since no reaction product is to formed at the interface. The results shown in Table 1 indicate that improving wettability causes a decrease in the recovery of matrix alloy from PRMMCs.

\begin{tabular}{ccccc} 
Matrix & $\begin{array}{l}\text { Reinforcement } \\
\text { Particle }\end{array}$ & $\begin{array}{l}\text { Fabricated } \\
\text { Temperature (K) }\end{array}$ & $\begin{array}{l}\text { Remelting } \\
\text { Temperature (K) }\end{array}$ & Recovery(\%) \\
\hline Al-7mass\%Si & $\mathrm{SiC}$ & 1073 & 1273 & 82 \\
& & 1273 & 1073 & 55 \\
& & 1073 & 1273 & 75 \\
& & 1273 & 1273 & 57 \\
\hline Cast Iron & $\mathrm{Al}_{2} \mathrm{O}_{3}$ & 1623 & 1623 & 94
\end{tabular}

Table 1 The effect of wettability between reinforcements and matrix alloy melt on the recovery of matrix alloy from PRMMCs.

\section{Conclusions}

1. The matrix alloy was separated from PRMMC specimens by a novel separation technique. It is considered that a skeleton structure would be formed near the nozzle part of silica container as a result of an aggregation of reinforcement particles, which acts as a filter to separate reinforcement particles from PRMMC specimens. 
2. The recovery increased with increasing the nozzle size. However, when the nozzle size was larger than $1.1 \mathrm{~mm}$ in diameter, the reinforcement particles were observed in the separated matrix alloy. It is suggested that an optimum nozzle size for the separation is around $0.75 \mathrm{~mm}$ in diameter.

3. In the case of that the particle volume fraction in the PRMMC specimen was lower than 20 vol\%, the recovery decreased gradually when the applied pressure on the melt surface was higher than $0.25 \mathrm{MPa}$ due to the formation of a preferential flow path. It is suggested that an optimum applied pressure for the separation is around $0.25 \mathrm{MPa}$.

4. The recovery decreases with increasing the volume fraction of reinforcement particles in PRMMC specimens due to the particle volume fraction approaching the fraction where a skeleton structure is formed. It is suggested that this novel separation technique is effective for PRMMCs with particle volume fraction lower than $30 \mathrm{vol} \%$.

5. An improved wettability resulting from the formation of a reaction layer on the surface of reinforcement particles prevents the separation of molten matrix alloy from reinforcement particles.

\section{References}

[1] H. Bansemir and O. Haider: Cryogenics, 38(1998) 51-59

[2] N. Asnafi, G. Langstedt, C. -H. Andersson, et al.: Thin-Walled Structures, 36(2000) 289-310

[3] V. Kamavaram, D. Mantha and R.G. Reddy: Electrochim. Acta 50(2005) 3286-3295

[4] Y. Nishida: Introduction to Metal Matrix Composites, pp. 154-167, Corona Publishing Corp., (2001)

[5] K. Ohishi, T. Morimoto, M. Mizumoto and A. Kagawa: J. JFS, 76(2004) 582-587

[6] K. Ohishi, S. Adachi, M. Mizumoto and A. Kagawa: J. JFS, 76(2004) 915-920

[7] M. Mizumoto, T. Murano and A. Kagawa: J. Japan Inst. Metals, 66 (2002) 371-376

[8] M. Mizumoto, T. Murano and A. Kagawa: Materials Transactions, JIM, 43(2002) 2629-2634

[9] M. Mizumoto, Y. Tajima and A, Kagawa: Materials Transactions, JIM, 45(2004) 1769-1773

[10] M. Mizumoto, Y. Kaneko and A, Kagawa: J. Japan Inst. Metals, 68(2004) 1047-1052

[11] M. Mizumoto, H. Ezaki and A. Kagawa: Material Science Forum, 475-479(2005) 2559-2562

[12] T. Fan, D. Zhang, T. Shibayanagi, et al.: Composites, Part A 34(2003) 291-299

[13]E. A. Aguilara, C. A. Leon, A. Contrerasa, et al.: Composites, Part A 33(2002) 1425-1428 